\title{
Non-linear elastic model incorporating temperature effects
}

Hong Liu MEng, BEng (Hons)

$\mathrm{PhD}$ candidate, School of Civil Engineering, Chongqing University, Chongqing, China

Hanlong Liu PhD, MEng, BEng (Hons)

Professor and Chair, School of Civil Engineering, Chongqing University, Chongqing, China

Yang Xiao PhD, MEng, BEng (Hons), SMASCE

Associate Professor, China Key Laboratory of New Technology for

Construction of Cities in Mountain Area (Chongqing University), Ministry

of Education, Chongqing, China; School of Civil Engineering, Chongqing

University, Chongqing, China (corresponding author: hhuxyanson@163.com)

\author{
Qingsheng Chen PhD \\ Research Fellow, Department of Civil and Environmental Engineering, \\ National University of Singapore, Singapore \\ Yufeng Gao PhD \\ Professor and Director, School of Civil and Transportation Engineering, \\ Hohai University, Nanjing, China \\ Jing Peng BEng (Hons) \\ Lecturer, School of Civil Engineering, Chongqing University, Chongqing, \\ China
}

The objective of this paper is to present a non-linear elastic model, considering temperature effects, that engineers can readily use to predict the mechanical behaviours of soils in geotechnical applications. Instead of using hyperbolic and exponential models, a non-linear equation is first formatted to describe the tangent moduli for saturated clays by introducing only one additional parameter (i.e. $\theta$ ). By extending the non-linear equation, a new simplified nonlinear elastic model is obtained that is capable of capturing well the stress-strain relationship of saturated clays at room temperature. Thereafter, based on experimental results, the relationships between cohesion, internal friction angle, index, tangent bulk modulus and temperature are developed and incorporated in the non-linear elastic model. A revised semi-regression method is also developed to determine the relationship between the additional model parameter $\theta$ and temperature. In this model, all of the eight parameters for the model have clear physical meanings and could be readily obtained by performing temperature-controlled triaxial tests. The accuracy and general applicability of the proposed method was checked by comparing its predictions with experimental results on saturated clay under various stress-path and temperature conditions as well as existing solutions proposed elsewhere.

\section{Notation}

$a, b, k, n$,

constants

$\gamma_{c}, \gamma_{\phi}, \gamma_{\theta}, k_{b}$,

$\gamma_{k}, m_{0}$ and $\gamma_{m}$

$B_{\mathrm{t}}$

$c$

$c_{0}$

$E_{\mathrm{i}}$

$E_{\text {te }}$

$E_{\text {th }}$

$E_{\mathrm{tp}}$

$O_{\mathrm{CR}}$

$p_{\mathrm{a}}$

$p^{\prime}$

$R_{\mathrm{f}}$

$T$

$T_{0}$

$\varepsilon_{\mathrm{a}}$

$\theta$

$\sigma_{1}$

$\sigma_{3}$

$\left(\sigma_{1}-\sigma_{3}\right)$

$\left(\sigma_{1}-\sigma_{3}\right)_{\mathrm{f}}$

$\left(\sigma_{1}-\sigma_{3}\right)_{\mathrm{u}}$ tangent bulk modulus: $\mathrm{kPa}$

cohesion at target temperature: $\mathrm{kPa}$ cohesion at room temperature: $\mathrm{kPa}$ initial tangent modulus: $\mathrm{kPa}$ tangent modulus in the exponential model: $\mathrm{kPa}$ tangent modulus in the hyperbolic model: $\mathrm{kPa}$ tangent modulus in the power function model: $\mathrm{kPa}$

overconsolidation ratio atmospheric pressure: $\mathrm{kPa}$ effective confining pressure: $\mathrm{kPa}$ failure ratio target temperature: ${ }^{\circ} \mathrm{C}$ initial ambient room temperature: ${ }^{\circ} \mathrm{C}$ axial strain: \% index in the power function model maximum principal stress: $\mathrm{kPa}$ minimum principal stress: $\mathrm{kPa}$ deviatoric stress: $\mathrm{kPa}$ deviatoric stress at the failure state: $\mathrm{kPa}$ deviatoric stress at the ultimate state: $\mathrm{kPa}$ $\phi$

$\phi_{0}$ internal friction angle at target temperature: ${ }^{\circ}$ internal friction angle at room temperature: ${ }^{\circ}$

\section{Introduction}

Over recent years, the influence of temperature on the engineering properties of soils has received increasing attention from researchers, due to its wide applications in the constructions of various energy-related infrastructures such as nuclear waste repositories (Gens et al., 2009), high-voltage electric cables (Brandon et al., 1989; Rao et al., 2017; Sun et al., 2011), energy piles (Abdelaziz and Ozudogru, 2016; Knellwolf et al., 2011; Saggu and Chakraborty, 2016) and geothermal structures (Brandl, 2006), highway pavements (Bianchini et al., 2011; Kertesz and Sansalone, 2014), thermally active embankments (Coccia and McCartney, 2013) and thermally active retaining walls (Stewart et al., 2014).

The volume change for saturated soils performs a transition from contractive to expansive behaviour during drained heating or the temperature cycle with increasing overconsolidation ratio $\left(O_{\mathrm{CR}}\right)$ (Abuel-Naga et al., 2006; Baldi et al., 1988; Cekerevac and Laloui, 2004; Romero et al., 2005) or relative density (Ng et al., 2016). Some experimental test results showed that the shear strength of saturated clays under both drained and undrained conditions would increase with increase in temperature (Abuel- 
Naga et al., 2006; Cekerevac and Laloui, 2004), while some other studies revealed a reduction in the shear strength with increasing temperature (Bruyn and Thimus, 1996; Kuntiwattanakul et al., 1995).

Meanwhile, many advanced thermo-mechanical constitutive models have been proposed to evaluate the mechanical behaviours of saturated and unsaturated soils undergoing temperature changes (Coccia and McCartney, 2016; Modaressi and Laloui, 1997; Najari and Selvadurai, 2013; Wang et al., 2016). Hueckel et al. (1998) put forward one of the first thermo-mechanical constitutive models for saturated clays considering thermal softening within the framework of the critical state theory. By employing the framework of the modified Cam-clay model, Cui et al. (2000) proposed a temperaturedependent model, which could be capable of predicting well the plastic strains at higher $O_{\mathrm{CR}}$ values. Graham et al. (2001) revised the Cam-clay model to consider the effects of temperature on the volume changes, pore water pressures and shear strengths for both normally consolidated and overconsolidated clays. Hamidi et al. (2014) used the relationships of the isotropic compression curves for saturated clays at various temperatures to find a new thermal-elastic-plastic mechanical model incorporating the stress history influence.

However, most of these temperature-dependent constitutive models mentioned previously are based on the elasto-plastic Camclay or modified Cam-clay model in the critical state framework. These models often include a number of parameters which may not have physical meanings or that have values difficult to determine due to the complicated soil properties, particularly considering the effects of temperature. Compared with these elastic-plastic models, it is easier to understand the theory of nonlinear elastic models, and the parameters could also be easily determined by performing triaxial compression tests (Hicher and Chang, 2006, 2008). In addition, the non-linear elastic models (e.g. Duncan-Chang model) could be readily implemented in finite-element analysis software without a singular matrix (Chen and Liu, 2007; Taciroglu and Hjelmstad, 2002; Xiong and Fang, 2008; Zheng and Binienda, 2008). Therefore, there is a pressing need to present a non-linear elastic model that considers temperature effects, that engineers can readily use to predict the mechanical behaviours of soils in geotechnical applications.

The main objective of this paper is to propose a new non-linear elastic model to capture the mechanical behaviours of saturated clays incorporating effects of temperature based on the general framework of the power function and the regression analysis method. In this model, the effects of temperature on the cohesion, internal friction angle and index for saturated clays are taken into account. The accuracy and general applicability of the proposed method is checked by comparing its predictions with experimental results and existing solutions proposed elsewhere.

\section{Power function non-linear elastic model}

The stress-strain relationship of saturated soils can be expressed by the following equations
- hyperbolic model (Duncan and Chang, 1970)

$$
\text { 1. } \sigma_{1}-\sigma_{3}=\frac{\varepsilon_{\mathrm{a}}}{a+b \varepsilon_{\mathrm{a}}}
$$

- exponential model (Gitau et al., 2006)

$$
\text { 2. } \sigma_{1}-\sigma_{3}=\left(\sigma_{1}-\sigma_{3}\right)_{\mathrm{u}}\left\{1-\exp \left[-\frac{E_{\mathrm{i}} \varepsilon_{\mathrm{a}}}{\left(\sigma_{1}-\sigma_{3}\right)_{\mathrm{u}}}\right]\right\}
$$

where $\sigma_{1}-\sigma_{3}$ is the deviatoric stress, $\left(\sigma_{1}-\sigma_{3}\right)_{\mathrm{u}}$ is the deviatoric stress for soils at the ultimate state, $\varepsilon_{\mathrm{a}}$ is the axial strain and $E_{\mathrm{i}}$ is the initial tangent modulus.

The tangent moduli of these non-linear models can be estimated from the derivation of Equations 1 and 2 and can be described as follows

3. $E_{\mathrm{th}}=E_{\mathrm{i}}\left[1-\frac{\left(\sigma_{1}-\sigma_{3}\right)}{\left(\sigma_{1}-\sigma_{3}\right)_{\mathrm{u}}}\right]^{2}$

4. $E_{\mathrm{te}}=E_{\mathrm{i}}\left[1-\frac{\left(\sigma_{1}-\sigma_{3}\right)}{\left(\sigma_{1}-\sigma_{3}\right)_{\mathrm{u}}}\right]$

where $E_{\mathrm{th}}$ and $E_{\mathrm{te}}$ are the tangent moduli in the hyperbolic and exponential models, respectively.

It can be seen that the tangent moduli in Equations 3 and 4 are identical in formation except for the indices. The index for the tangent modulus in the hyperbolic model is 2 , while its counterpart is 1 in the exponential model. Due to this, the power function model is a traditional type of non-linear elastic model; it may be reasonable to employ a unique power function model instead of using the hyperbolic and exponential models to describe the tangent modulus, and it can be given as follows

5. $E_{\mathrm{tp}}=E_{\mathrm{i}}\left[1-\frac{\left(\sigma_{1}-\sigma_{3}\right)}{\left(\sigma_{1}-\sigma_{3}\right)_{\mathrm{u}}}\right]^{\theta}$

where $E_{\mathrm{tp}}$ is the tangent modulus in the power function model and $\theta$ is the index of the power function non-linear elastic model.

Then, the non-linear stress-strain behaviour of saturated soils at room state in the power function can be rewritten as

6.

$$
\sigma_{1}-\sigma_{3}=\left(\sigma_{1}-\sigma_{3}\right)_{\mathrm{u}}\left\{1-\left[1+\frac{(\theta-1) E_{\mathrm{i}}}{\left(\sigma_{1}-\sigma_{3}\right)_{\mathrm{u}}} \varepsilon_{\mathrm{a}}\right]^{1 /(1-\theta)}\right\}
$$


Non-linear elastic model incorporating

temperature effects

Liu, Liu, Xiao et al. in which

7. $R_{\mathrm{f}}=\frac{\left(\sigma_{1}-\sigma_{3}\right)_{\mathrm{f}}}{\left(\sigma_{1}-\sigma_{3}\right)_{\mathrm{u}}}$

8. $\left(\sigma_{1}-\sigma_{3}\right)_{\mathrm{f}}=\frac{2 c \cos \phi+2 \sigma_{3} \sin \phi}{1-\sin \phi}$

9. $E_{\mathrm{i}}=k p_{\mathrm{a}}\left(\frac{\sigma_{3}}{p_{\mathrm{a}}}\right)^{n}$

where $\left(\sigma_{1}-\sigma_{3}\right)_{\mathrm{f}}$ is the deviatoric stress for soils at the failure state; $R_{\mathrm{f}}$ is the failure ratio, which is the ratio between the deviatoric stresses at the failure and ultimate states; $c$ is the cohesion; $\phi$ is the internal friction angle; $p_{\mathrm{a}}$ is the atmospheric pressure of $101 \mathrm{kPa}$; and $k$ and $n$ are the material constants, respectively. The derivation of the relationship described by Equation 6 can be seen in the Appendix.

The combination of Equations 6-9 gives

$$
\begin{aligned}
& \sigma_{1}-\sigma_{3}=\frac{2 c \cos \phi+2 \sigma_{3} \sin \phi}{(1-\sin \phi) R_{\mathrm{f}}} \\
& \times\left\{1-\left[1+\frac{(\theta-1)(1-\sin \phi) R_{\mathrm{f}}}{2 c \cos \phi+2 \sigma_{3} \sin \phi} k p_{\mathrm{a}}\left(\frac{\sigma_{3}}{p_{\mathrm{a}}}\right)^{n} \varepsilon_{\mathrm{a}}\right]^{1 /(1-\theta)}\right\}
\end{aligned}
$$

10.

As shown in Equation 10, only one additional parameter (i.e. $\theta$ ) is required in the proposed power function model, compared with the traditional hyperbolic model or exponential model. Although there are some slight variations (Guo et al., 2014), these three parameters (i.e. $R_{\mathrm{f}}, k$ and $n$ ) remain relatively constant with change in temperature for saturated soils. It may be reasonable to take the average values of these parameters determined by the Duncan and Chang (1970) equations at each target temperature. The determination of the thermal related parameters (i.e. $c, \phi$ and $\theta)$ is presented in the following section.

\section{Determination of model parameters}

Parameters $c$ and $\phi$

The results of tests conducted by Guo (2014) on Ningbo soft clay, Uchaipichat and Khalili (2009) on Bourke silt, Soleimanbeigi et al. (2014) on recycled asphalt shingle mixtures and Cekerevac and Laloui (2004) on kaolin clay are depicted in Figures 1 and 2 as normalised temperature plotted against cohesion and internal friction angle. It should be taken into account that all the test data used in these figures are calculated in the saturated condition. In the figures, the solid lines stand for the simulation results which

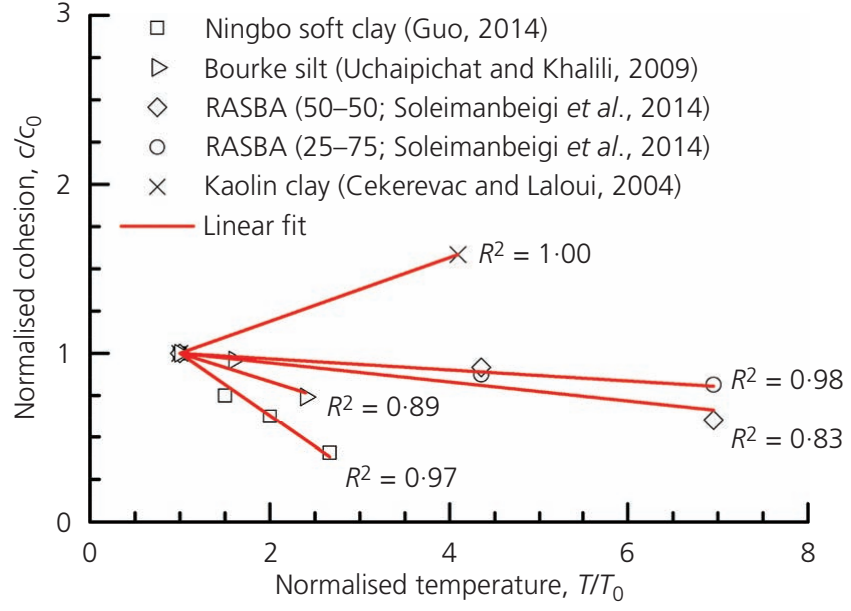

Figure 1. Influence of temperature on the cohesion of soils. RASBA, recycled asphalt shingle-bottom ash mixture

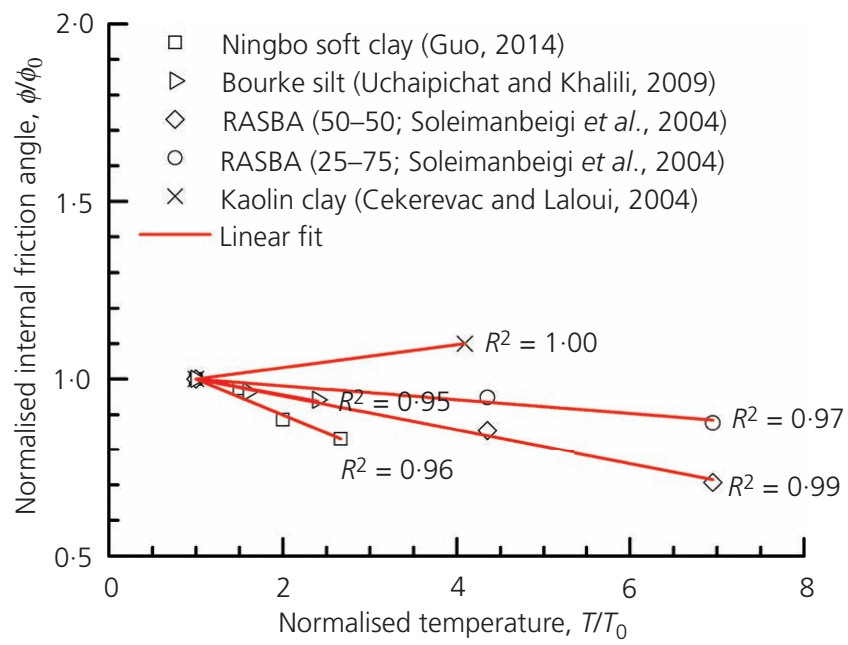

Figure 2. Influence of temperature on the internal friction angle of soils

are determined from the test data. Interestingly, it can be seen that the relationships of cohesion, internal friction angle and temperature are essentially linear and can be expressed by the following equations

11. $c=c_{0}\left[1+\gamma_{\mathrm{c}}\left(T / T_{0}-1\right)\right]$

12. $\phi=\phi_{0}\left[1+\gamma_{\phi}\left(T / T_{0}-1\right)\right]$

where $c_{0}$ and $\phi_{0}$ are the cohesion and internal friction angle of soils at room temperature, respectively. $T$ and $T_{0}$ are the target and room temperatures, respectively. $\gamma_{c}$ and $\gamma_{\phi}$ are the material constants. 


\section{Parameter $\theta$}

The determination of index $\theta$ can be classified into two categories.

The first category is the full regression method. Xu and Jin (2000) took the test data (i.e. $\sigma_{1}-\sigma_{3}$ and $\varepsilon_{\mathrm{a}}$ ) into Equation 6 and produced the value of the deviatoric stress at the ultimate state $\left(\sigma_{1}-\sigma_{3}\right)_{\mathrm{u}}$, initial tangent modulus $E_{\mathrm{i}}$ and index $\theta$ by regression analysis directly. In this method, there are two knowns (i.e. $\sigma_{1}-$ $\sigma_{3}$ and $\left.\varepsilon_{\mathrm{a}}\right)$ and three unknowns (i.e. $\left(\sigma_{1}-\sigma_{3}\right)_{\mathrm{u}}, E_{\mathrm{i}}$ and $\theta$ ), so it may be not easy to achieve an exact solution during the regression analysis process, thereby possibly leading to an unacceptable deviation between the predictions and test data.

The second category is the semi-regression method. Cai et al. (2012) calculated the deviatoric stress at the ultimate state $\left(\sigma_{1}-\sigma_{3}\right)_{\mathrm{u}}$ and the initial tangent modulus $E_{\mathrm{i}}$ using Equations 7-9 and then put these values as well as the test data (i.e. $\sigma_{1}-\sigma_{3}$ and $\varepsilon_{a}$ ) into Equation 6 to obtain a result for index $\theta$ through semi-regression analysis. In this method, there is only one unknown (i.e. $\theta$ ), the exact value of which could be readily determined, thereby leading to a very good agreement of the model predictions with the test data. However, compared with the first method, the values of $\left(\sigma_{1}-\sigma_{3}\right)_{\mathrm{u}}$ and $E_{\mathrm{i}}$ are determined from the experimental data in the second method; the predictions become very sensitive to the accuracy of the test data.

To overcome the issues in the preceding methods, in this work, a revised semi-regression method is proposed through combination of the two regression methods mentioned earlier to evaluate the index $\theta$. In this method, the deviatoric stress at the ultimate state $\left(\sigma_{1}-\sigma_{3}\right)_{\mathrm{u}}$ and initial tangent modulus $E_{\mathrm{i}}$ are calculated by using Equations 7-9, 11 and 12 in terms of the predicted results (rather than the test data). In addition, the predicted values of $\left(\sigma_{1}-\sigma_{3}\right)_{\mathrm{u}}$ and $E_{\mathrm{i}}$ and the test data for $\sigma_{1}-\sigma_{3}$ and $\varepsilon_{\mathrm{a}}$ at different confining pressure and temperature conditions are used for Equation 6 to reach a solution for index $\theta$ by performing semi-regression analysis. In the revised semiregression method, there are four knowns (i.e. $\left(\sigma_{1}-\sigma_{3}\right)_{\mathrm{u}}, E_{\mathrm{i}}, \sigma_{1}-\sigma_{3}$ and $\varepsilon_{a}$ ) and only one unknown (i.e. $\theta$ ), so it may be easy to get the solution with precision compared to the full regression method. Otherwise, two knowns (i.e. $\left(\sigma_{1}-\sigma_{3}\right)_{\mathrm{u}}$ and $\left.E_{\mathrm{i}}\right)$ are the predicted results, so the revised regression method may be not sensitive to the test data compared to the semi-regression method. As indicated in Figure 3, the index $\theta$ with regard to the temperature can be linearly expressed as follows

13. $\theta=\theta_{0}+\gamma_{\theta}\left(T / T_{0}-1\right)$

where $\theta_{0}$ is the index $\theta$ in the power function model for soils at room temperature and $\gamma_{\theta}$ is the material constant.

\section{Parameter $B_{\mathrm{t}}$}

The tangent bulk modulus $B_{\mathrm{t}}$ of the power function model is similar to that of the hyperbolic model and can be described by the following function

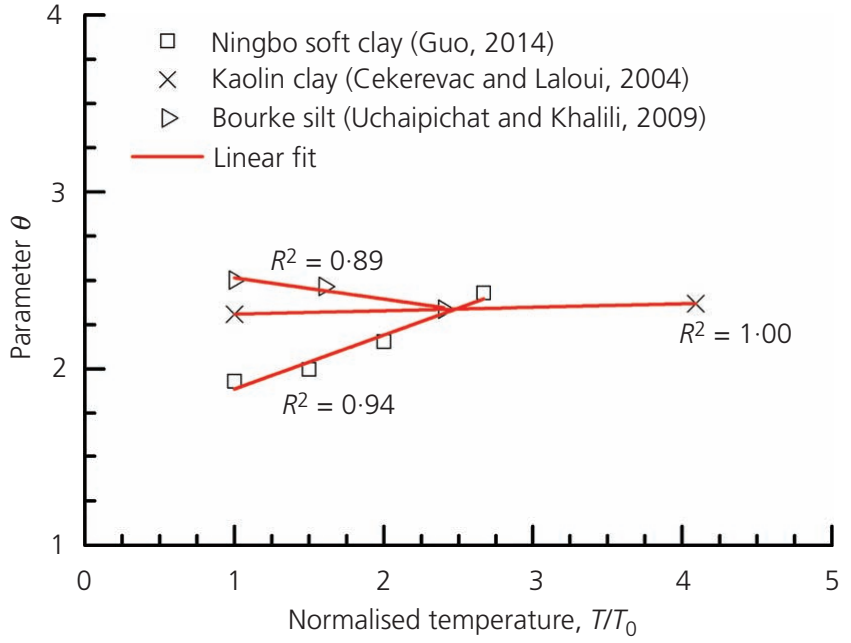

Figure 3. Influence of temperature on the index $\theta$

14. $B_{\mathrm{t}}=k_{b} p_{\mathrm{a}}\left(\frac{\sigma_{3}}{p_{\mathrm{a}}}\right)^{m}$

in which

15. $k_{b}=k_{b 0}+\gamma_{k}\left(T / T_{0}-1\right)$

16. $m=m_{0}+\gamma_{\mathrm{m}}\left(T / T_{0}-1\right)$

where $k_{b}$ and $m$ are the material parameters related to the temperature, $k_{b 0}$ and $m_{0}$ are the initial values of $k_{b}$ and $m$ at room temperature and $\gamma_{k_{b}}$ and $\gamma_{\mathrm{m}}$ are the material constants.

Combining Equations 14-16, the tangent bulk modulus $B_{\mathrm{t}}$ incorporating the effects of temperature changes can be given as follows

17. $B_{\mathrm{t}}=\left[k_{b 0}+\gamma_{k}\left(T / T_{0}-1\right)\right] p_{\mathrm{a}}\left(\frac{\sigma_{3}}{p_{\mathrm{a}}}\right)^{m_{0}+\gamma_{\mathrm{m}}\left(T / T_{0}-1\right)}$

\section{Validation of the proposed model}

In this section, the newly proposed thermo-mechanical constitutive model is validated against the temperature-controlled triaxial test data reported by Guo (2014) and Cekerevac and Laloui (2004). The material parameters of soils are listed in Table 1. In addition, the performance of this model is compared with the predictions of the model proposed by Yao and Zhou (2013), which was developed based on the unified hardening theory but requires more model parameters.

\section{Undrained triaxial test}

Guo (2014) reported the results of temperature-controlled triaxial compression tests on the Ningbo soft clay. The clay specimens 
Geotechnical Research

Volume 5 Issue GR1
Non-linear elastic model incorporating

temperature effects

Liu, Liu, Xiao et al.

Table 1. Material parameters of saturated soils for numerical study

\begin{tabular}{|c|c|c|c|c|c|c|c|c|c|}
\hline Experimental data & $\gamma_{c}$ & $\gamma_{\phi}$ & $O_{\mathrm{CR}}$ & $\gamma_{\theta}$ & $\gamma_{k}$ & $\gamma_{m}$ & $k$ & $n$ & $R_{\mathrm{f}}$ \\
\hline Guo (2014) & -0.37 & $-0 \cdot 10$ & $1 \cdot 0$ & $0 \cdot 31$ & - & - & $34 \cdot 00$ & 0.70 & 0.74 \\
\hline Cekerevac and Laloui (2004) & 0.19 & 0.03 & $\begin{array}{l}1 \cdot 0 \\
1 \cdot 2 \\
1 \cdot 5 \\
2 \cdot 0 \\
3 \cdot 0 \\
6 \cdot 0\end{array}$ & $\begin{array}{r}0.02 \\
-0.09 \\
0.05 \\
-0.04 \\
0.12 \\
0.29\end{array}$ & 4.08 & $-0 \cdot 11$ & $93 \cdot 86$ & 0.41 & 0.79 \\
\hline
\end{tabular}

were initially consolidated under three isotropic confining pressures (i.e. 50, 100 and $200 \mathrm{kPa}$ ) at room temperature. For each confining pressure, four temperatures $\left(30,45,60\right.$ and $\left.80^{\circ} \mathrm{C}\right)$ were applied under drained conditions. Further, after drained heating, specimens were sheared under undrained conditions to investigate the effects of temperature on the shear strength of saturated Ningbo soft clay. According to the test data, it can be evaluated that the cohesion and internal friction angle of saturated Ningbo soft clay decrease with an increase in temperature as shown in Figures 4 and 5. However, as the temperature increases, the index $\theta$ also increases to a high value as shown in Figure 6 . Figure 7 shows the measured and predicted stress-strain relationships of clays at different confining pressure and temperature conditions. A reduction in strength for Ningbo soft clay during the undrained shearing phase with increasing temperature is predicted by the power function model and is in good agreement with the laboratory data.

\section{Drained triaxial test}

Cekerevac and Laloui (2004) carried out a series of temperaturecontrolled triaxial tests to evaluate the thermal mechanical behaviour of saturated, overconsolidated kaolin clay. The specimens were initially pre-consolidated to $600 \mathrm{kPa}$ at $22^{\circ} \mathrm{C}$ and then unloaded to $600,500,400,300,200$ and $100 \mathrm{kPa}$, thereby leading to different overconsolidation ratios $\left(O_{\mathrm{CR}}=1 \cdot 0,1 \cdot 2,1 \cdot 5\right.$,

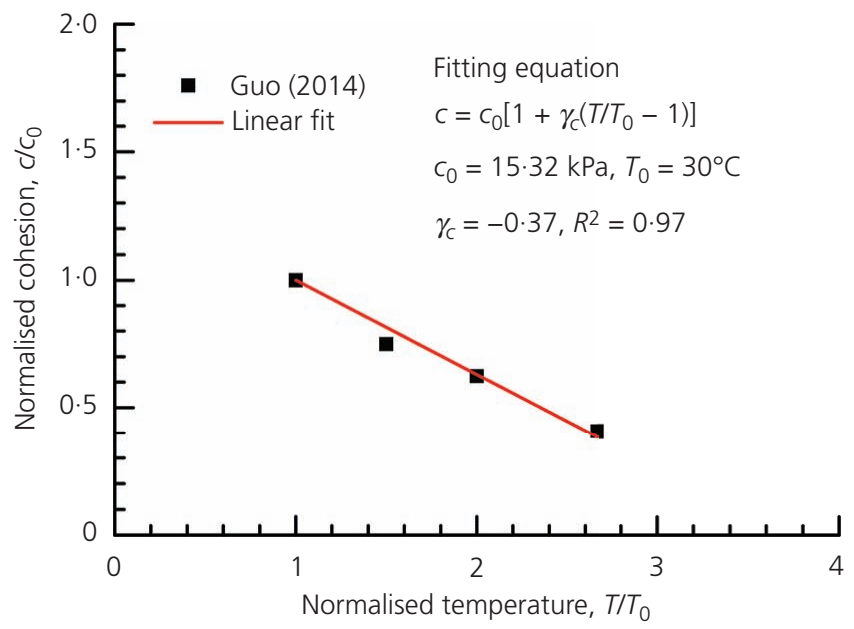

Figure 4. Calibration for model parameter c (data from Guo (2014))

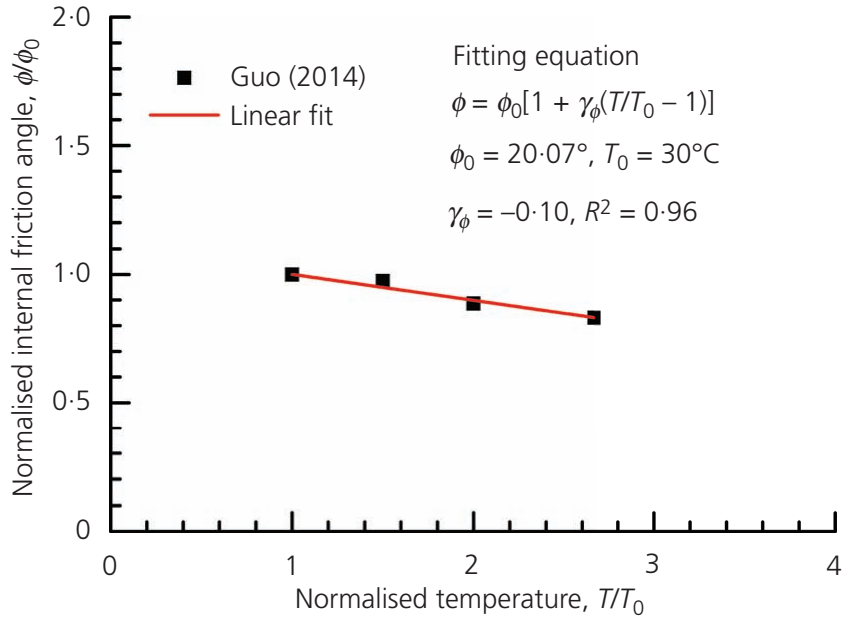

Figure 5. Calibration for model parameter $\phi$ (data from Guo (2014))

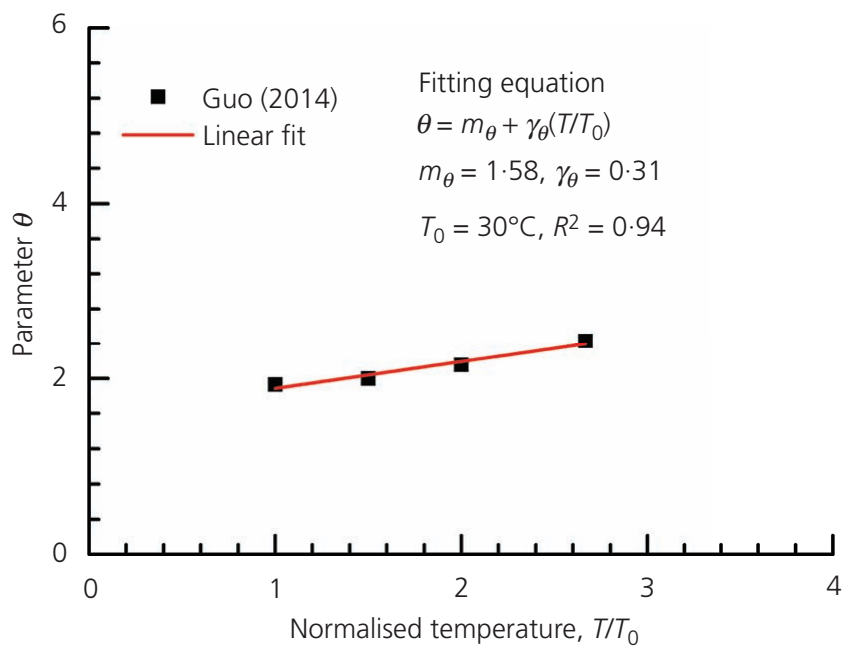

Figure 6. Calibration for model parameter $\theta$ (data from Guo (2014))

$2 \cdot 0,3 \cdot 0,6 \cdot 0)$. After completion of consolidation, the specimens were heated up to $90^{\circ} \mathrm{C}$ at a rate of $3.33^{\circ} \mathrm{C} / \mathrm{h}$ under drained conditions. These specimens were sheared in the drained condition to $30 \%$ of the axial strain at two different constant temperature conditions (i.e. $T=22$ and $90^{\circ} \mathrm{C}$ ). 


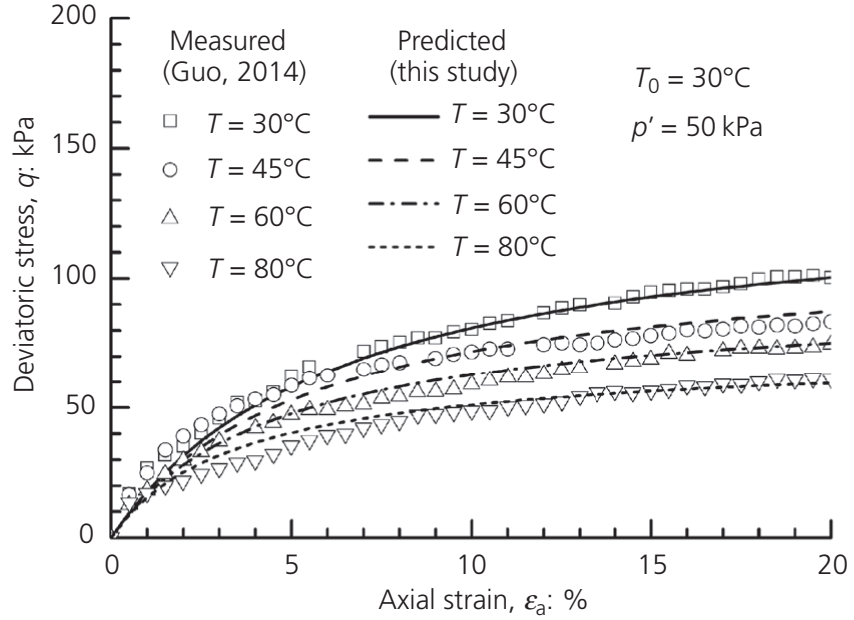

(a)

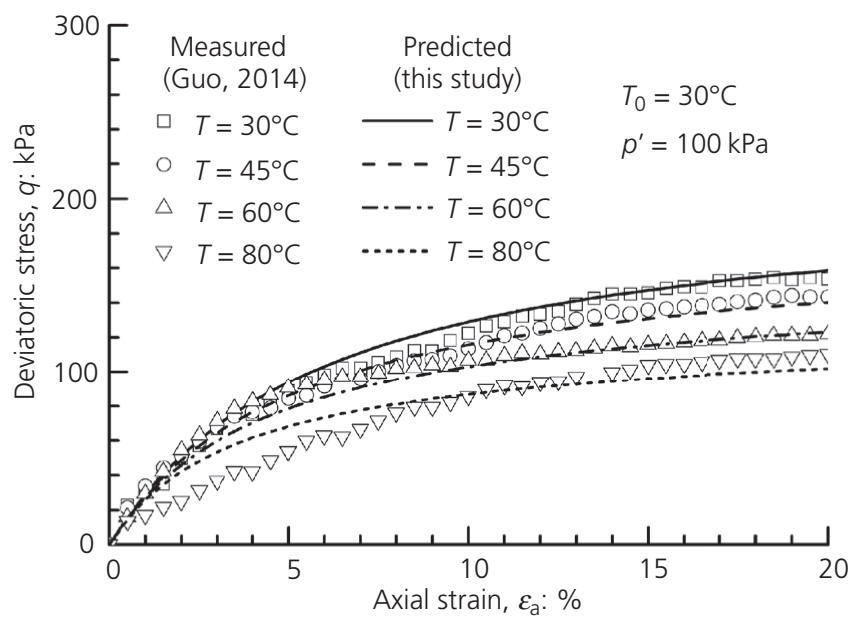

(b)

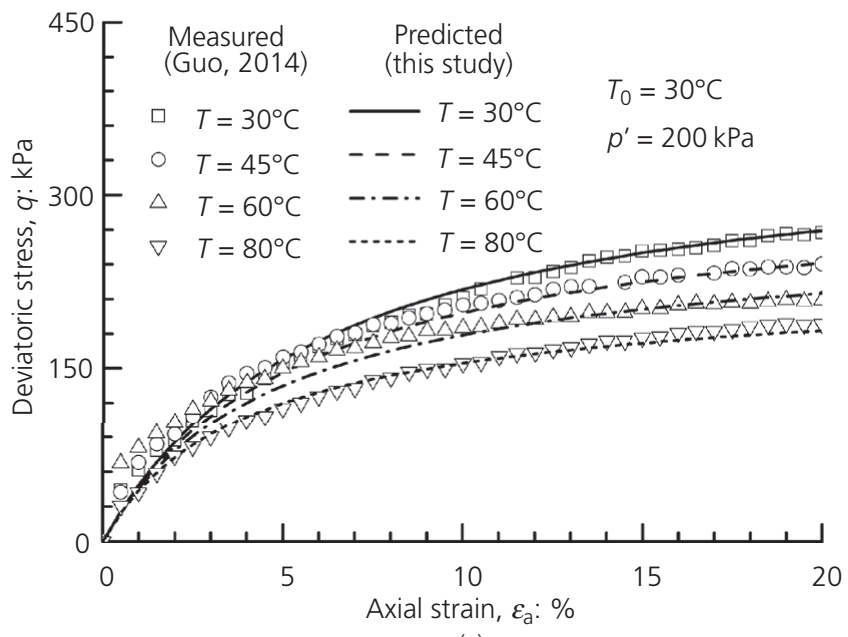

(c)

Figure 7. Model predictions against experimental data (data from Guo (2014)): (a) $p^{\prime}=50 \mathrm{kPa}$; (b) $p^{\prime}=100 \mathrm{kPa}$; (c) $p^{\prime}=200 \mathrm{kPa}$

The stress-strain relationships of kaolin clay are predicted by the power function non-linear elastic model and compared with the test results as shown in Figure 8. The predicted responses using the thermal-elastic-plastic model developed by Yao and Zhou (2013) are also included in Figure 8. It can be observed that an increase in temperature leads to an increase in the strength of soils for all $O_{\mathrm{CR}}$ values, which is predicted well by the non-linear elastic model. In addition, the softening behaviour during shearing for heavily overconsolidated specimens is not predicted by this non-linear model. However, the general trend of predictions seems acceptable.

\section{Conclusions}

A new isotropically thermal mechanical constitutive model for normally and lightly overconsolidated clays was developed in present work by extending the existing hyperbolic model (Duncan and Chang, 1970) and exponential model (Gitau et al., 2006). Instead of using the hyperbolic and exponential functions, a unique power function model is employed to describe the tangent modulus with only one additional parameter (i.e. $\theta$ ). In terms of experimental results, linear equations are proposed to capture the effects of temperature on the cohesion and internal friction angle of soils. In addition, a revised semi-regression method was used to determine the accurate value of the index, with an attempt to reach a very good agreement of the model predictions with the test data. All of the nine model parameters for the model have clear physical meanings and could be readily obtained by performing temperaturecontrolled triaxial tests. The accuracy and general applicability of the proposed method was checked by comparing its predictions with experimental results and existing solutions proposed elsewhere.

\section{Acknowledgements}

The authors would like to acknowledge the financial support for the project from the National Natural Science Foundation of China (Grant Number 51378178 and Grant Number 51678094), the PhD programmes of the Foundation of Ministry of Education of China (Grant Number 20130094140001) and 111 Program (B13024). The authors also thank Z. Guo, Drs A. Uchaipichat, A. Soleimanbeigi, and L. Laloui for providing their experimental data. 
Non-linear elastic model incorporating

temperature effects

Liu, Liu, Xiao et al.

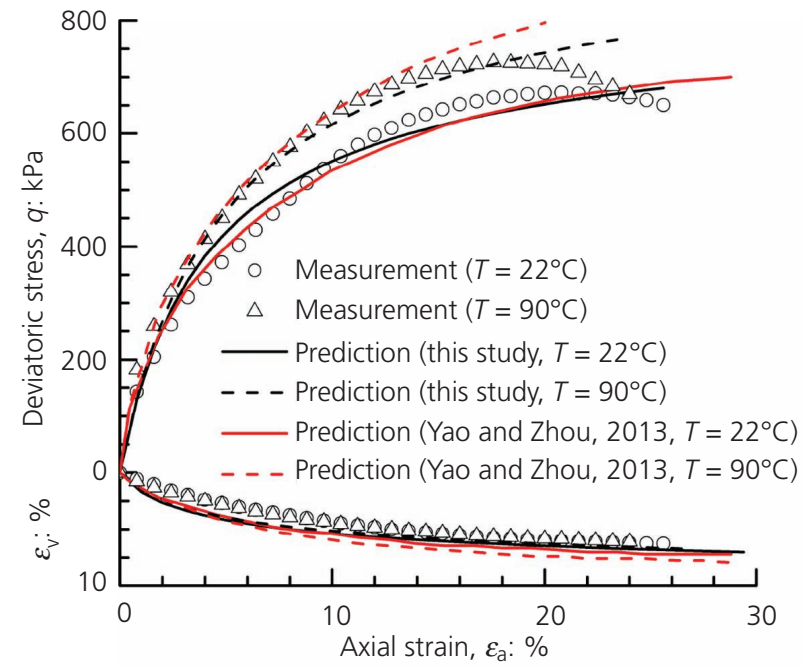

(a)

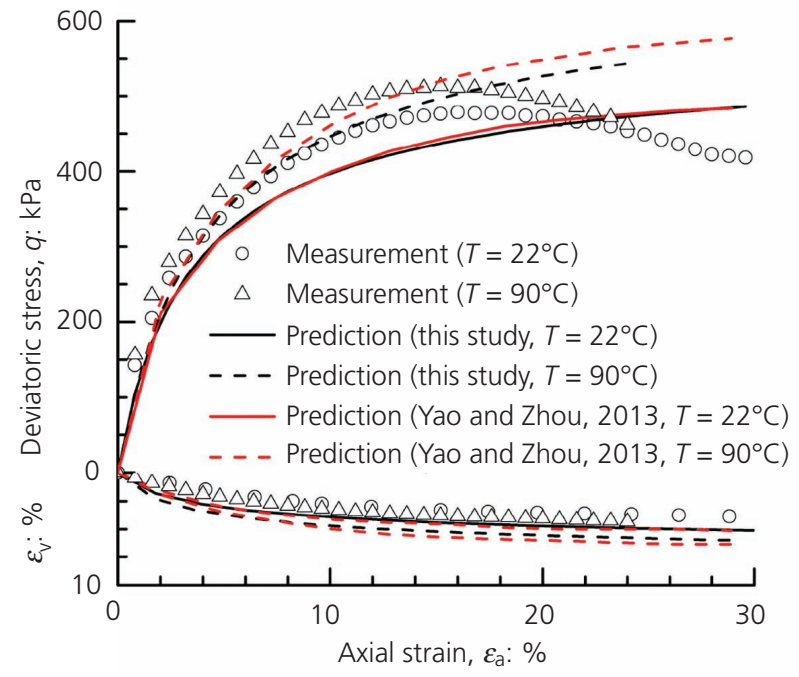

(c)

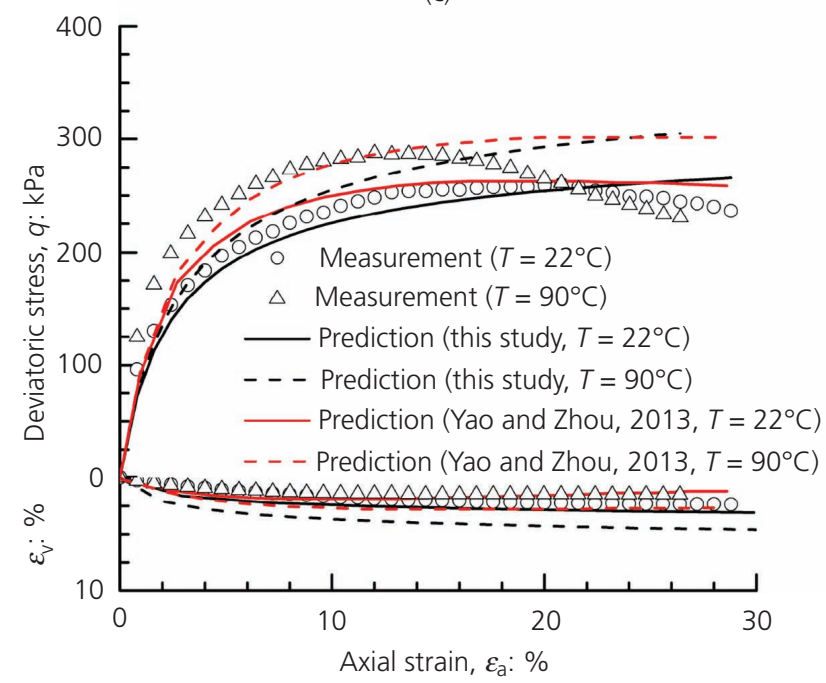

(e)

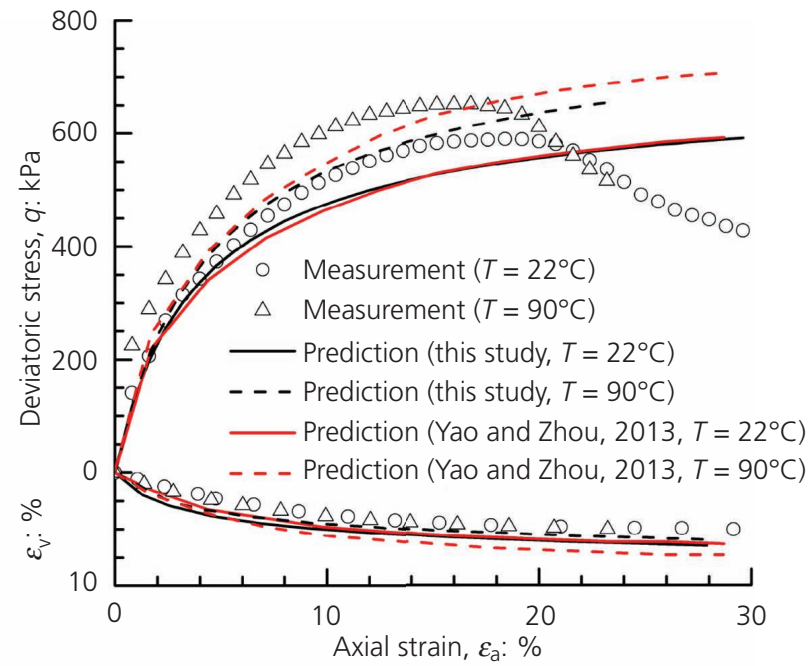

(b)

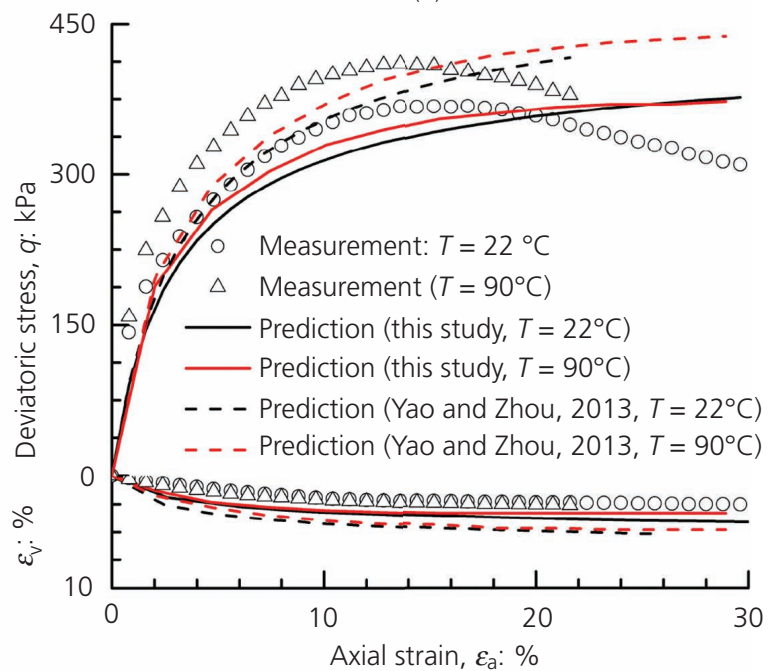

(d)

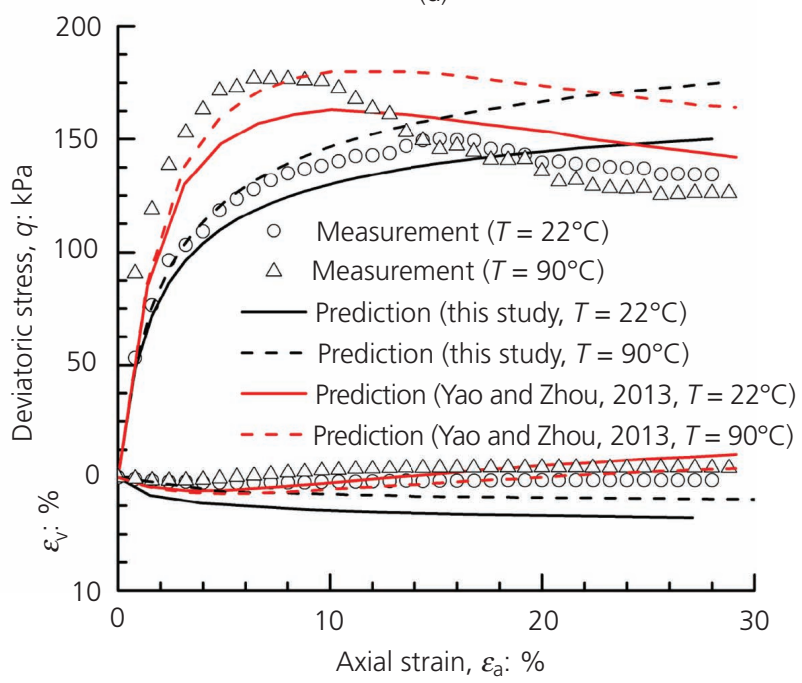

(f)

Figure 8. Model predictions against experimental data on remoulded kaolin clay (data from Cekerevac and Laloui (2004)): (a) $O_{\mathrm{CR}}=1 \cdot 0$; (b) $O_{C R}=1 \cdot 2$; (c) $O_{C R}=1 \cdot 5$; (d) $O_{C R}=2 \cdot 0$; (e) $O_{C R}=3 \cdot 0$; (f) $O_{C R}=6 \cdot 0$ 


\section{Appendix}

The tangent modulus can be assumed in a power function, given as follows

18. $E_{\mathrm{tp}}=E_{\mathrm{i}}\left[1-\frac{\left(\sigma_{1}-\sigma_{3}\right)}{\left(\sigma_{1}-\sigma_{3}\right)_{\mathrm{u}}}\right]^{\theta}$

In addition, the tangent modulus of saturated soils during the conventional triaxial test can be defined as

19. $E_{\mathrm{tp}}=\frac{\mathrm{d} \sigma_{1}}{\mathrm{~d} \varepsilon_{\mathrm{a}}}=\frac{\mathrm{d}\left(\sigma_{1}-\sigma_{3}\right)}{\mathrm{d} \varepsilon_{\mathrm{a}}}$

Equations 18 and 19 can be rewritten as

20. $\left[1-\frac{\left(\sigma_{1}-\sigma_{3}\right)}{\left(\sigma_{1}-\sigma_{3}\right)_{\mathrm{u}}}\right]^{-\theta} \mathrm{d}\left(\sigma_{1}-\sigma_{3}\right)=E_{\mathrm{i}} \mathrm{d} \varepsilon_{\mathrm{a}}$

Integration of Equation 20 gives

21. $\left[1-\frac{\left(\sigma_{1}-\sigma_{3}\right)}{\left(\sigma_{1}-\sigma_{3}\right)_{\mathrm{u}}}\right]^{1-\theta}\left(\sigma_{1}-\sigma_{3}\right)_{\mathrm{u}}=(\theta-1)\left(E_{\mathrm{i}} \varepsilon_{\mathrm{a}}+C\right)$

Reduction of the fraction to a common denominator gives

$\left[\left(\sigma_{1}-\sigma_{3}\right)_{\mathrm{u}}-\left(\sigma_{1}-\sigma_{3}\right)\right]^{1-\theta}=(\theta-1)\left(E_{\mathrm{i}} \varepsilon_{\mathrm{a}}+C\right)\left[\left(\sigma_{1}-\sigma_{3}\right)_{\mathrm{u}}\right]^{-\theta}$

22.

If $\theta \neq 1$ the stress and strain behaviour of soils can be written as follows

$$
\begin{aligned}
& \sigma_{1}-\sigma_{3} \\
= & \left(\sigma_{1}-\sigma_{3}\right)_{\mathrm{u}}-\left[\left(\sigma_{1}-\sigma_{3}\right)_{\mathrm{u}}\right]^{-\theta /(1-\theta)}\left[(\theta-1)\left(E_{\mathrm{i}} \varepsilon_{\mathrm{a}}+C\right)\right]^{1 /(1-\theta)} \\
= & \left(\sigma_{1}-\sigma_{3}\right)_{\mathrm{u}}-\left(\sigma_{1}-\sigma_{3}\right)_{\mathrm{u}}\left[\left(\sigma_{1}-\sigma_{3}\right)_{\mathrm{u}}\right]^{-1 /(1-\theta)}\left[(\theta-1)\left(E_{\mathrm{i}} \varepsilon_{\mathrm{a}}+C\right)\right]^{1 /(1-\theta)} \\
= & \left(\sigma_{1}-\sigma_{3}\right)_{\mathrm{u}}\left\{1-\left[\frac{\theta-1}{\left(\sigma_{1}-\sigma_{3}\right)_{\mathrm{u}}}\left(E_{\mathrm{i}} \varepsilon_{\mathrm{a}}+C\right)\right]^{1 /(1-\theta)}\right\}
\end{aligned}
$$

23.

If $\theta=1$ it can be replaced by 0.99999 or 1.00001 , and the stress-strain relationship also can be described by Equation 23 .

During the conventional triaxial test, the test data should pass through the point $(0,0)$ on the $\left(\sigma_{1}-\sigma_{3}\right)-\varepsilon_{\mathrm{a}}$ plane. And then, the constant can be obtained as follows
24. $C=\frac{\left(\sigma_{1}-\sigma_{3}\right)_{\mathrm{u}}}{\theta-1}$

Therefore, the stress-strain relationship of soils using the power non-linear elastic model at room state can be given as follows

25. $\sigma_{1}-\sigma_{3}=\left(\sigma_{1}-\sigma_{3}\right)_{\mathrm{u}}\left\{1-\left[1+\frac{(\theta-1) E_{\mathrm{i}}}{\left(\sigma_{1}-\sigma_{3}\right)_{\mathrm{u}}} \varepsilon_{\mathrm{a}}\right]^{1 /(1-\theta)}\right\}$

\section{REFERENCES}

Abdelaziz S and Ozudogru TY (2016) Non-uniform thermal strains and stresses in energy piles. Environmental Geotechnics 3(4): 237-252, https://doi.org/10.1680/jenge.15.00032.

Abuel-Naga HM, Bergado DT, Ramana GV et al. (2006) Experimental evaluation of engineering behavior of soft Bangkok clay under elevated temperature. Journal of Geotechnical and Geoenvironment Engineering 132(7): 902-910, https://doi.org/10.1061/(ASCE)10900241(2006)132:7(902).

Baldi G, Hueckel T and Pellegrini R (1988) Thermal volume changes of the mineral-water system in low-porosity clay soils. Canadian Geotechnical Journal 25(4): 807-825, https://doi.org/10.1139/t88-089.

Bianchini A, Heitzman M and Maghsoodloo S (2011) Evaluation of temperature influence on friction measurements. Journal of Transportation Engineering 137(9): 640-647, https://doi.org/10.1061/ (ASCE)TE.1943-5436.0000271.

Brandl H (2006) Energy foundations and other thermo-active ground structures. Géotechnique 56(2): 81-122, https://doi.org/10.1680/geot. 2006.56.2.81.

Brandon TL, Mitchell JK and Cameron JT (1989) Thermal instability in buried cable backfills. Journal of Geotechnical Engineering 115(1): 38-55, https://doi.org/10.1061/(ASCE)0733-9410(1989)115:1(38).

Bruyn DD and Thimus JF (1996) The influence of temperature on mechanical characteristics of Boom clay - the results of an initial laboratory program. Engineering Geology 41(1-4): 117-126, https://doi.org/10.1016/0013-7952(95)00029-1.

Cai YY, Zheng CT, Qi ZB, Mu K and Yu J (2012) Nonlinear constitutive model of clay based on power function. Journal of Lanzhou University of Technology 38(4): 126-130.

Cekerevac C and Laloui L (2004) Experimental study of thermal effects on the mechanical behaviour of a clay. International Journal for Numerical and Analytical Methods in Geomechanics 28(3): 209-228, https://doi.org/10.1002/nag.332.

Chen YM and Liu HL (2007) Development and implementation of Duncan-Chang constitutive model in FLAC ${ }^{3 \mathrm{D}}$. Rock and Soil Mechanics 28(10): 2123-2126.

Coccia CJR and McCartney JS (2013) Impact of heat exchange on the thermo-hydro-mechanical response of reinforced embankments. In Proceedings of Geo-congress 2013: Stability and Performance of Slopes and Embankments III (Meehan C, Pradel D, Pando MA and Labuz JF (eds)). American Society of Civil Engineers, Reston, VA, USA, pp. 343-352.

Coccia CJR and McCartney JS (2016) Thermal volume change of poorly draining soils II: model development and experimental validation. Computers and Geotechnics 80: 16-25, https://doi.org/10.1016/j. compgeo.2016.06.010.

Cui YJ, Nabil S and Pierre D (2000) A thermomechanical model for saturated clays. Canadian Geotechnical Journal 37(3): 607-620, https://doi.org/10.1139/t99-111. 
Duncan JM and Chang CY (1970) Nonlinear analysis of stress and strain in soils. Journal of the Soil Mechanics and Foundations Division 96(5): 1629-1653.

Gens A, Sanchez M, Guimaraes LD et al. (2009) A full-scale in situ heating test for high-level nuclear waste disposal: observations, analysis and interpretation. Géotechnique 59(4): 377-399, https://doi.org/10.1680/geot.2009.59.4.377.

Gitau AN, Gumbe LO and Biamah EK (2006) Influence of soil water on stress-strain behaviour of a compacting soil in semi-arid Kenya. Soil and Tillage Research 89(2): 144-154, https://doi.org/10.1016/j.still. 2005.07.008

Graham J, Tanaka N, Crilly T and Alfaro M (2001) Modified Cam-Clay modelling of temperature effects in clays. Canadian Geotechnical Journal 38(3): 608-620, https://doi.org/10.1139/t00-125.

Guo Z (2014) The Study of Consolidation and Strength Characteristics of Soft Clay in Ningbo Area under Different Temperatures. MSc thesis, Ningbo University, Zhejiang, China.

Guo Z, Liu GB, Yin TF, Zheng RY and Deng YB (2014) Test study on parameters of Duncan-Chang model for soft clay with consideration of temperature influence. Building Structure 44(3): 93-96.

Hamidi A, Tourchi S and Khazaei C (2014) Thermomechanical constitutive model for saturated clays based on critical state theory. International Journal of Geomechanics 15(1): 04014038, https://doi.org/10.1061/ (ASCE)GM.1943-5622.0000402.

Hicher PY and Chang CS (2006) Anisotropic nonlinear elastic model for particulate materials. Journal of Geotechnical and Geoenvironment Engineering 132(8): 1052-1061, https://doi.org/10.1061/(ASCE)10900241(2006)132:8(1052).

Hicher PY and Chang CS (2008) Elastic model for partially saturated granular materials. Journal of Engineering Mechanics 134(6): 505-513, https://doi.org/10.1061/(ASCE)0733-9399(2008)134:6(505)

Hueckel T, Rita P and Carlos DO (1998) A constitutive study of thermoelasto-plasticity of deep carbonatic clays. International Journal for Numerical and Analytical Methods in Geomechanics 22(7): 549-574, https://doi.org/10.1002/(SICI)1096-9853(199807)22:7\%3C549::AIDNAG927\%3E3.3.CO\%3B2-I.

Kertesz R and Sansalone J (2014) Hydrologic transport of thermal energy from pavement. Journal of Environmental Engineering 140(8): 04014028, https://doi.org/10.1061/(ASCE)EE.1943-7870. 0000831 .

Knellwolf C, Peron H and Laloui L (2011) Geotechnical analysis of heat exchanger piles. Journal of Geotechnical and Geoenvironmental Engineering 137(10): 890-902, https://doi.org/10.1061/(ASCE)GT. 1943-5606.0000513.

Kuntiwattanakul P, Ikuo T, Kanta O and Ichiro S (1995) Temperature effects on undrained shear characteristics of clay. Soils and Foundations 35(1): 147-162, https://doi.org/10.3208/sandf1972. 35.147.

Modaressi H and Laloui L (1997) A thermo-viscoplastic constitutive model for clays. International Journal for Numerical and Analytical Methods in Geomechanics 21(5): 313-335, https://doi.org/10.1002/ (SICI)1096-9853(199705)21:5\%3C313::AID-NAG872\%3E3.3.CO\% 3B2-X.
Najari M and Selvadurai APS (2013) Thermo-hydro-mechanical response of granite to temperature changes. Environmental Earth Science 72(1): 189-198, https://doi.org/10.1007/s12665-013-2945-3.

Ng CWW, Wang SH and Zhou C (2016) Volume change behaviour of saturated sand under thermal cycles. Géotechnique Letters $\mathbf{6}(2)$ 124-131, https://doi.org/10.1680/jgele.15.00148.

Rao PP, Chen QS, Nimbalkar S and Liu Y (2017) Laboratory study on impulse current characteristics of clay. Environmental Geotechnics 4(3): 199-208, https://doi.org/10.1680/jenge.15.00027.

Romero E, Villar MV and Lloret A (2005) Thermo-hydro-mechanical behaviour of two heavily overconsolidated clays. Engineering Geology 81(3): 255-268, https://doi.org/10.1016/j.enggeo.2005.06.011.

Saggu R and Chakraborty T (2016) Thermomechanical response of geothermal energy pile groups in sand. International Journal of Geomechanics 16(4): 04015100, https://doi.org/10.1061/(ASCE)GM. 1943-5622.0000567.

Soleimanbeigi A, Edil TB and Benson CH (2014) Effect of temperature on geotechnical properties of recycled asphalt shingle mixtures. Journal of Geotechnical and Geoenvironment Engineering 141(2): 04014097, https://doi.org/10.1061/(ASCE)GT. 1943-5606.0001216.

Stewart MA, Coccia CJR and McCartney JS (2014) Issues in the implementation of sustainable heat exchange technologies in reinforced, unsaturated soil structures. In Proceedings of Geo-congress 2014 (Abu-Farsakh M and Hoyos L (eds)). American Society of Civil Engineers, Reston, VA, USA, GSP 234, pp. 4066-4075.

Sun G, Chen Z and Liu Z (2011) Analytical and experimental investigation of thermal expansion mechanism of steel cables. Journal of Materials in Civil Engineering 23(7): 1017-1027, https://doi.org/10.1061/ (ASCE)MT.1943-5533.0000271

Taciroglu E and Hjelmstad KD (2002) Simple nonlinear model for elastic response of cohesionless granular materials. Journal of Engineering Mechanics 128(9): 969-978, https://doi.org/10.1061/ (ASCE)0733-9399(2002)128:9(969).

Uchaipichat A and Khalili N (2009) Experimental investigation of thermo-hydro-mechanical behaviour of an unsaturated silt. Géotechnique 59(4): 339-353, https://doi.org/10.1680/ geot.2009.59.4.339.

Wang LZ, Wang KJ and Hong Y (2016) Modeling temperature-dependent behavior of soft clay. Journal of Engineering Mechanics 142(8): 04016054, https://doi.org/10.1061/(ASCE)EM.1943-7889.0001108.

Xiong YC and Fang YG (2008) Secondary development of material constitutive model in ADINA software. Rock and Soil Mechanics 29(8): 2221-2225.

Xu HF and Jin FN (2000) Power function model of shear deformation for rock joints. Chinese Journal of Rock Mechanics and Engineering 19(3): 314-317.

Yao YP and Zhou AN (2013) Non-isothermal unified hardening model: a thermo-elasto-plastic model for clays. Géotechnique $\mathbf{6 3 ( 1 5 )}$ 1328-1345, https://doi.org/10.1680/geot.13.P.035.

Zheng XH and Binienda WK (2008) Rate-dependent shell element composite material model implementation in LS-DYNA. Journal of Aerospace Engineering 21(3): 140-151.

\section{How can you contribute?}

To discuss this paper, please submit up to 500 words to the editor at journals@ice.org.uk. Your contribution will be forwarded to the author(s) for a reply and, if considered appropriate by the editorial board, it will be published as a discussion in a future issue of the journal. 